\title{
Optimization of the calculation time in simulation using the GATE/ GEANT4 Monte Carlo of radiotherapy treatment plans for small fields
}

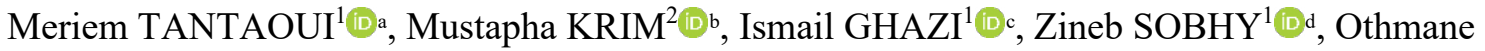 \\ KAANOUCH $^{2,3} \mathbb{D e}^{\mathrm{e}}$, Abdelkrim KARTOUNI ${ }^{1}{ }^{\mathrm{f}}$, Souha SAHRAOUI ${ }^{4} \mathbb{D}^{\mathrm{g}}$

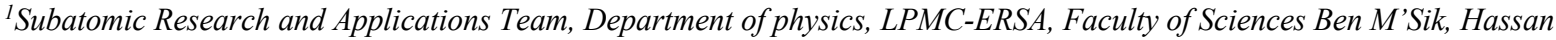 \\ II University, Casablanca, Morocco \\ ${ }^{2}$ Laboratory of Sciences and Health Technologies, High Institute of Health Sciences (ISSS), Hassan I University, BP 555, \\ Settat, Morocco \\ ${ }^{3}$ Department of Radiotherapy, Sheikh Khalifa International University Hospital, BP 82403, Casablanca, Morocco \\ ${ }^{4}$ Center Mohammed VI for treatment of cancer, Ibn Rochd University Hospital, 20360 Casablanca, Morocco \\ meriem.tantaoui-etu@etu.univh2c.ma,.mustapha.krim@uhp.ac.ma
}

Keywords: $\quad$ Radiotherapy, Flattening Filter, Dosimetry, time, Monte Carlo, GATE/GEANT4.

Abstract: $\quad$ Radiation therapy is one of the most widely used methods of treating cancer. One of the therapeutic gains of this method is to save in terms of calculation time during treatment planning, the variance reduction method is one of the most used to reduce the calculation time except that there are other alternatives to be able to optimize as much as possible, hence the interest of this study. In this work, we compared by Monte-Carlo simulation the flattened and unflattened $6 \mathrm{MV}$ photon beams of the VARIAN Clinac 2100 linear accelerator. All the elements of the accelerator were simulated and allowed us to reproduce very close to reality. The doses obtained by simulation were taken in a tank of water under reference conditions, source to surface distance (SSD) of $100 \mathrm{~cm}$, the arm at $0^{\circ}$ and for a field variation of $2 \times 2 \mathrm{~cm}^{2}, 3 \times 3 \mathrm{~cm}^{2}, 4 \times 4 \mathrm{~cm}^{2}, 5 \times 5 \mathrm{~cm}^{2}, 10 \times$ $10 \mathrm{~cm}^{2}, 20 \times 20 \mathrm{~cm}^{2}, 30 \times 30 \mathrm{~cm}^{2}, 40 \times 40 \mathrm{~cm}^{2}$. For each field, we calculated using a beam with a flattening filter (FF) and another beam with flattening filter-free (FFF). The calculation time of all these simulations was recorded. The results showed that the shape of the dose profiles changes according to the FF and FFF mode with a very interesting change for fields greater than $5 \times 5 \mathrm{~cm}^{2}$ and almost similar profiles for the fields $2 \times 2 \mathrm{~cm}^{2}, 3 \times 3 \mathrm{~cm}^{2}, 4 \times 4 \mathrm{~cm}^{2}, 5 \times 5 \mathrm{~cm}^{2}$. The region between $80 \%$ and $100 \%$ of doses for beams with $\mathrm{FF}$ contributes to dose uniformity while for FFF fields gives the appearance of symmetry of dose distribution for all fields combined. On the depth dose curves (PDD) the dose at the entry into FFF mode was greater than that of FF mode leading to an increase in the influence of photons, the latter thus important on the increase in dose rate. The computation time in FF mode is higher by a proportion factor of 0.85 to 7.36 compared to the FFF mode respectively by going from the field $2 \times 2 \mathrm{~cm}^{2}$ to $40 \times 40 \mathrm{~cm}^{2}$. This comparison leads to being able to neglect the flattening filter for fields smaller than $5 \times 5 \mathrm{~cm}^{2}$ since it has no impact on the processing field but has a great impact on the calculation time and to have a mode without this filter for fields smaller than 5 $\mathrm{x} 5 \mathrm{~cm}^{2}$ leads to an optimization of the computation time of 1.35 times compared to the FF mode.

\footnotetext{
a (iD https://orcid.org/0000-0001-9425-3380

b(D) https://orcid.org/0000-0001-9938-2843

c(iD) https://orcid.org/0000-0002-5293-7386

d(D) https://orcid.org/0000-0001-5860-5086

e(iD) https://orcid.org/0000-0003-3857-2082

f(iD https://orcid.org/0000-0003-4404-2467

g(D) https://orcid.org/0000-0003-1169-3087
} 